\title{
Regime-Switching in Emerging Stock Market Returns*
}

\author{
Kodjovi G. Assoe \\ Ecole des Hautes Etudes Commerciales, Canada
}

Many emerging markets have experienced significant changes in government policies and capital market reforms. These changes may lead to changes in their return-generating processes. Based on Markov-switching models, this paper investigates whether there is more than one regime in the return-generating processes of nine emerging markets and the specific characteristics of each regime. The results show very strong evidence of regime-switching behavior in emerging stock market returns. The two regimes through which emerging markets evolve are different whether one takes the domestic investors' perspective or that of foreign investors. For foreign investors, changes in volatility seem to be the main characteristic of emerging market regimes. The implications of these findings for the stability of emerging stock markets are discussed (JEL F21, F30, G12, G15).

Keywords: emerging markets, regime-switching, international investment.

\section{Introduction}

Over the last two decades, the evolution of many emerging markets suggests that the characteristics of these markets should have changed, as well as the stochastic behavior of their return-generating processes. While some emerging markets have a long history, they grew exponentially only recently in terms of market capitalization, number of listed companies, and trading volume (Goetzmann and Jorion [1999]).

\footnotetext{
*The author would like to thank Simon van Norden, Narjess Boubakri, the pariticipants of 1999 FMA and MFS meetings, Geoffery Booth, and Peter Theodossiou (managing editor) for their helpful comments and suggestions. Financial support from the Centre d'Etudes en Administration Internationale (CETAI) is gratefully acknowledged.
}

(Multinational Finance Journal, 1998, vol. 2, no. 2, pp. 101-132

(C) Multinational Finance Society, a nonprofit corporation. All rights reserved.

DOI: $10.17578 / 2-2-2$ 
Soaring returns and good prospects for economic growth have fueled a surge of interest in emerging markets which have become more accessible to global investors owing to the financial liberalization policies over the 80's (Domowitz et al. [1997]; Bekaert [1995]). The microstructure of most emerging markets has changed markedly to accommodate investors from industrialized countries even though a high liquidity risk, a limited number of available assets, a shortage of good quality, and large capitalization shares remain the main differences between emerging and mature markets (Richards [1996]). Furthermore, as noted by Erb et al. (1997) and Bekaert et al. (1997), the common characteristic of emerging markets is the high degree of their countryrisk (political risk, economic risk, and financial risk), and currency devaluations, failed economic plans, coups, financial shocks, regulatory changes, and capital market reforms occurred at different levels in almost all of the emerging markets during the last decades.

Many articles have focused on the behavior of emerging market returns during recent years. Harvey (1995) finds that emerging market returns are more predictable than developed market returns and the predictability could be induced by fundamental and operational inefficiencies of these markets (Richards [1996]). Ghysels and Garcia (1996) indicate that the structure of the emerging markets' returns distribution is unstable by rejecting the structural stability of the Harvey's (1995) prediction model. Bekaert and Harvey (1995 and 1997) show that many emerging markets are becoming more and more integrated into the world capital market because of the increased importance of world factors on emerging market expected returns. Harvey (1995) and Bekaert (1995) find that, contrary to what would be expected from a capital asset pricing framework, higher systematic risks are associated with lower expected returns in many emerging markets.

It is widely documented that emerging stock market returns exhibit higher conditional volatility and probability of large price changes, persistence in conditional volatility, and time-varying conditional moments (De Santis and Imrohoroglu [1997], Bekaert et al. [1997], and To and Assoe [1996]). Though ARCH-type models are used to provide a parsimonious representation of these market return series, recent results from De Frontnouvelle (1999) and Schaller and Van Norden (1997) suggest that the regime-switching in the underlying datagenerating process could induce a non-linearity in stock market returns 
which could show up in ARCH tests. Furthermore, while To and Assoe (1996) have documented the presence of unit roots in characterization of the emerging market return series, results from Perron (1989) indicate that changes in regime may give the spurious impression of unit roots in the series. Many emerging markets have displayed several large fluctuations in asset prices that are hardly explained by changes in market fundamentals. The existence of bubbles in emerging markets (Williamson [1993]) can result in a switching behavior in stock prices where an apparent deviation from fundamentals grows in one regime and shrinks in the second regime (van Norden and Vigfusson [1998]; van Norden and Schaller [1993]). ${ }^{1}$ Therefore, the main motivation behind this article is to investigate whether there is evidence of regimeswitching in emerging market return series, and the main characteristics of each regime. There is a huge evidence of non-normalities in emerging market returns (Bekaert et al. [1998; 1997], Bekaert and Harvey [1997]) that may be explained by regime-switching. In fact, it is well known that the mixture of two normal distributions results in a distribution that is leptokurtic relative to a normal distribution since the high-variance distribution fattens up the tails of the low-variance distribution. The mixture is also skewed when the means differ across the two distributions. Therefore, if a given emerging market passes through many regimes with different mean returns and variances, the distribution of returns in this market would be skewed and leptokurtic even if the sub-regime returns distributions are normal.

Bekaert and Harvey (1995) show that if a market is fully segmented from the world equity markets, the process generating the expected returns in this market should be different from the one arising if this market were integrated to the international markets. Using a two-state Markov-switching model where the market can switch from a segmented state to an integrated state, they find that a number of emerging markets have moved from segmented to integrated international markets. Hamilton and Susmel (1994) find that a Markovswitching model that allows discrete changes in the volatility process provides a better statistical fit to the weekly return series of the CRSP value-weighted portfolio of U.S. stocks than ARCH models without

1. In a bubble model of asset pricing, a rational risk-neutral investor may hold an asset that is overvalued relative to its fundamentals as long as its expected return equals the return of a non-overvalued or non-bubbly asset. 
switching, a result supported by Cai (1994). De Santis and Imrohoroglu (1997) examined a regime-switching GARCH model of emerging market returns. They used a deterministic regime-switching model by identifying the specific official date when each market switches from one regime (i.e., being fully segmented) to the other (i.e., being fully integrated). In their model, the process of regime-switching is irreversible in the sense that when the data-generating process switches from regime 1 to regime 2 , it cannot come back to regime 1 . In contrast to their model, Bekaert and Harvey (1995) allow markets to return to the regime of segmentation after they have been integrated. The regimeswitching models presented in this article do not rely on official liberalization dates of the emerging markets as in De Santis and Imrohoroglu (1997) or postulate the influence of known global factors on the emerging market returns as in Bekaert and Harvey (1995). Instead, it is assumed that, since emerging markets have passed through many changes during the last decades (e.g., currency pegging or a breaking of a peg, capital market reforms, regulatory changes, political instability), it is more likely that the return-generating process in these markets has changed.

The purpose of this article is to analyze the behavior of the time series of emerging market returns and volatilities in order to investigate the existence of different and changing regimes in these markets. Whether the means, the variances, or both the means and variances differ between regimes in emerging market returns is also investigated. This is done using a set of first-order regime-switching (FORS) models by Gray (1997). A standard Hamilton (1989) model nested within the FORS framework is examined, where the states follow a Markov process with constant transition probabilities. The results show very strong evidence of regime-switching behavior in emerging stock market returns whether these returns are expressed in local currencies or in U.S. dollars. The volatility switching models or the models where the regimes differ only in terms of market volatility better describe the return process when returns are expressed in U.S. dollars. On the other hand, the local currency returns in many emerging markets are drawn from two regimes with different means and standard deviations. These features have important implications for both international portfolio managers interested in investing in emerging markets and for researchers interested in modeling returns in these markets. For 
example, Kawakatsu and Morey (1998) raised the issue of the identification of the liberalization dates of emerging stock markets, a factor used by De Santis and Imrohoroglu (1997). Time series models presented in this article can be used to identify the regime-switching dates as the actual events dates (e.g., opening or liberalization dates). Therefore, they are complementary to the models based on fundamentals such as De Santis and Imrohoroglu (1997)'s. The ex ante probabilities of each regime generated by the models presented herein are of great interest for portfolio managers in forecasting the future regime of the emerging stock markets. The rest of the paper is organized as follows. In the next section, the data used in the study are presented along with some descriptive statistics on emerging market returns. Section III presents the structure of the model and provides evidence of two regimes in the distribution of emerging market returns. The results from the estimation of regime-switching models are presented in section IV and the conclusion follows in section V.

\section{Data and Descriptive Statistics}

Monthly stock market price indices from December 1975 to December 1997 for nine emerging markets are used herein, namely those of Argentina, Brazil, Chile, Greece, India, Korea, Mexico, Thailand, and Zimbabwe. The data are taken from the International Finance Corporation's Emerging Markets Data Base (EMDB). Biases related to market-microstructure-induced non-randomness (e.g., thin trading, price adjustment delays, price-discreteness-induced bias) and their impact on the return-generating process are reduced by using monthly instead of high-frequency data. Given that reliable inflation data in many emerging markets are not available and there is a lack of reliable shortterm interest rate data, total market returns expressed in local currencies and in U.S. dollars are used herein. ${ }^{2}$

The first four moments of the distribution of each market return

2. Results reported in this paper are mostly based on U.S. dollar returns data unless otherwise stated. Results based on local currency data are available from the author upon request. Excess returns (relative to the U.S. short-term interest rate) are not used since it is well documented that the U.S. interest rate process displays regime shifts (Garcia and Perron, [1996]; Gray, [1996]). 
series $R_{t}$ are estimated in the following joint GMM-system:

$$
\begin{gathered}
\varepsilon_{1, t}=R_{t}-\mu, \\
\varepsilon_{2, t}=\left(R_{t}-\mu\right)^{2}-\sigma^{2}, \\
\varepsilon_{3, t}=\frac{\left(R_{t}-\mu\right)^{3}}{\sigma^{3}}-\delta, \text { and } \\
\varepsilon_{4, t}=\frac{\left(R_{t}-\mu\right)^{4}}{\sigma^{4}}-3-k,
\end{gathered}
$$

where $\mu$ is the mean, $\sigma$ is the standard deviation, $\delta$ is the skewness, $\kappa$ is the excess kurtosis, and $\varepsilon_{t}=\left\{\varepsilon_{1, t} \varepsilon_{2, t} \varepsilon_{3, t} \varepsilon_{4, t}\right\}$ represents the disturbances with $E\left\{\varepsilon_{t}\right\}=0$. This system is estimated using the generalized method of moments (GMM). There are four orthogonality conditions and four parameters, which implies the model is exactly identified. The GMM normality test suggested by Richardson and Smith (1993) and the standard Bera-Jarque test of normality are performed. ${ }^{3}$

The estimated mean, standard deviation, skewness, kurtosis, and some information on the statistical properties of dollar returns for the nine emerging markets are displayed in table 1 . The mean monthly returns for the emerging markets ranges from .97\% (Greece) to $4.76 \%$ (Argentina) in U.S. dollar terms. They are all positive and significantly different from zero at the 5\% level, except for Greece and Zimbabwe. The four Latin American emerging markets in the sample (Argentina, Brazil, Chile, and Mexico) have average annual (compound) returns above $28 \%$ over the 22 -year period. Emerging market returns display high volatility as measured by their monthly standard deviations that range from $8.01 \%$ for India to $26.74 \%$ for Argentina. The standard deviations for five out of the nine emerging markets (i.e., Argentina,

3. The GMM normality test is just a Wald test for the skewness and excess kurtosis coefficients to be jointly equal to zero. The Bera-Jarque test statistic is given by $B J=\frac{n}{6}\left(\delta^{2}+.25 \kappa^{2}\right)$ where $n$ is the number of observations, $\delta$ is the skewness, and $\kappa$ is the excess kurtosis. $B J$ is asymptotically distributed as chi-squared with two degrees of freedom. 
TABLE 1. Summary Statistics

\begin{tabular}{|c|c|c|c|c|c|c|c|c|c|c|c|c|}
\hline \multirow[b]{2}{*}{ Country } & \multirow[b]{2}{*}{ Mean } & \multirow[b]{2}{*}{ Dev. } & \multirow[b]{2}{*}{ Min } & \multirow[b]{2}{*}{ Max } & \multirow[b]{2}{*}{ Skewness } & \multirow[b]{2}{*}{ Kurtosis } & \multicolumn{4}{|c|}{ Serial Correlations } & \multirow[b]{2}{*}{ GMM } & \multirow{2}{*}{$\begin{array}{l}\text { Bera- } \\
\text { Jarque }\end{array}$} \\
\hline & & & & & & & $\rho_{1}$ & $\rho_{2}$ & $\rho_{4}$ & $\rho_{12}$ & & \\
\hline Brazil & $.0213^{*}$ & $.1616^{*}$ & -.5689 & .5753 & $.51^{*}$ & $1.38 *$ & $\begin{array}{r}.04 \\
{[.4]}\end{array}$ & $\begin{array}{r}-.03 \\
{[.6]}\end{array}$ & $\begin{array}{c}-.08 \\
{[3.0]}\end{array}$ & $\begin{array}{r}.02 \\
{[11.9]}\end{array}$ & $\begin{array}{r}17.28 \\
(.00)\end{array}$ & $\begin{array}{l}31.7 \\
(.00)\end{array}$ \\
\hline Greece & $.0079 *$ & $.0968^{*}$ & -.3081 & .5858 & $1.78^{*}$ & $7.88^{*}$ & $\begin{array}{r}.13 \\
{[3.4]}\end{array}$ & $\begin{array}{r}.16 \\
{[10.2]}\end{array}$ & $\begin{array}{r}-.09 \\
{[11.4]}\end{array}$ & $\begin{array}{r}-.03 \\
{[27.2]}\end{array}$ & $\begin{array}{c}14.77 \\
(.00)\end{array}$ & $\begin{array}{r}811.6 \\
(.00)\end{array}$ \\
\hline India & $.0133^{*}$ & $.0801 *$ & -.2438 & .3527 & $.60 *$ & $1.68^{*}$ & $\begin{array}{r}.10 \\
{[2.2]}\end{array}$ & $\begin{array}{r}.01 \\
{[2.2]}\end{array}$ & $\begin{array}{r}.07 \\
{[3.9]}\end{array}$ & $\begin{array}{r}-.11 \\
{[12.1]}\end{array}$ & $\begin{array}{l}6.97 \\
(.03)\end{array}$ & $\begin{array}{r}46.1 \\
(.00)\end{array}$ \\
\hline Korea & .0097 & $.0938^{*}$ & -.3356 & .4484 & .50 & $2.64 *$ & $\begin{array}{r}.12 \\
{[4.2]}\end{array}$ & $\begin{array}{r}.12 \\
{[8.1]}\end{array}$ & $\begin{array}{r}.00 \\
{[8.4]}\end{array}$ & $\begin{array}{r}.11 \\
{[16.5]}\end{array}$ & $\begin{array}{l}6.53 \\
(.04)\end{array}$ & $\begin{array}{c}86.1 \\
(.00)\end{array}$ \\
\hline Mexico & $.0215^{*}$ & $.1240^{*}$ & -.5932 & .3960 & $-.84 *$ & $3.57 *$ & $\begin{array}{r}.25 \\
{[16.1]}\end{array}$ & $\begin{array}{r}-.05 \\
{[16.7]}\end{array}$ & $\begin{array}{r}.01 \\
{[17.6]}\end{array}$ & $\begin{array}{r}-.02 \\
{[30.4]}\end{array}$ & $\begin{array}{l}8.58 \\
(.01)\end{array}$ & $\begin{array}{r}168.7 \\
(.00)\end{array}$ \\
\hline
\end{tabular}

Note: Summary statistics relating to monthly emerging market returns. Returns are in U.S. dollars, and from January 1976 to December 1997 . The means, standard deviations, skewness and kurtosis coefficients are jointly estimated via GMM for each market. $\rho_{1}$ are serial correlations or autocorrelations of order $i$ $(i=1,2,4$ and 12) and the values under brackets are the Ljung-Box Q-statistics up to $i$ lags (these statistics are chi-squared distributed with i degree of freedom; critical values at the 5\% level are 3.84, 5.99, 9.49 and 21.03 respectively for $i=1,2,4$ and 12). Statistics from the GMM test and the traditional Bera-Jarque test for normality are reported with their p-values (in parentheses). * denotes statistics (the first four moments) significantly different from 0 at the $5 \%$ level. 
Brazil, Chile, Mexico, and Zimbabwe) are greater than 10\%. The sample period maximum and minimum monthly returns displayed in table 1 also reveal the large swings of the emerging market returns. These returns are highly auto-correlated since the first-order autocorrelations of the Chile, Greece, India, Mexico, and Zimbabwe's market returns are greater than .10. Mexico displays a first-order autocorrelation of .26, the highest among the emerging markets, while South Korea market returns are the least auto-correlated. Positive autocorrelation may be explained by insider traders who have superior information or by a group of uninformed traders who generally extrapolate past return behavior while making their investment decisions.

Except for Korea, Thailand, and Zimbabwe, where the coefficient of skewness is not significantly different from zero at the 5\% level, and for Mexico, which displays a negative and statistically significant skewness, the remaining emerging markets exhibit positive and statistically significant coefficient of skewness. Moreover, the excess kurtosis coefficients are positive and significantly different from zero for all emerging market returns, except for Chile at the 5\% level. The GMM test for normality and the Bera-Jarque normality test statistics unambiguously show that the distributions of the nine emerging market returns are non-normal. The results based on local currency returns are not materially different.

\section{Testing for a Markov Regime-Switching}

The general framework of the model is presented and then restricted to a two-regime Markov switching model. Within this framework, tests for whether there is more than one regime in the return-generating processes of the emerging markets are performed.

\section{A. General Model Setting}

Let $S_{t}$ be a discrete, latent indicator variable that identifies which of the $N$ regimes the market is in at time $t$. That is, $S_{t}=i$, where $i=1,2, \ldots, N$. Investors don't know in which regime the market is and, after the fact, they can only estimate the conditional probability that the market was in a given regime $i$. For example, in a two-state switching model, $S_{t}=1$ 
and $S_{t}=2$ may be a segmented market regime and an integrated market regime, respectively, or a regime of surviving bubbles and a regime of collapsing bubbles, or a high-volatility regime and a low-volatility regime, etc.

Changes in regime can affect the mean return, the volatility, or both of these moments of the return distribution. To assess these effects, Hamilton's regime-switching models are considered with constant transition probabilities within the Gray's (1997) FORS framework. In other words, the state variable $S_{t}$ follows a first-order Markovian process. The advantage of using this process in modeling regimeswitching in emerging stock markets is that it allows investors to generate meaningful forecasts that take into account the possibility of the change from one regime to another. Therefore, the ex ante probability of being in regime $i$ at time $t$ conditional on the information available at $t-1, \Phi_{t-1}$, and denoted by $p_{i, t}=\operatorname{prob}\left(S_{t}=i \mid \Phi_{t-1}\right)$ is of great importance to investors for forecasting purposes. Furthermore, the transition or switching probabilities from one regime to another help investors to assess the duration of each regime. For example, if $\pi_{i, i}=$ $\operatorname{prob}\left(S_{t}=i \mid S_{t-1}=i\right)$, the expected duration of regime $i$ is given by $\left(1-\hat{\pi}_{i, i}\right)^{-1}$. The following general representation of the return process, $R_{t}$, is postulated for each emerging market:

$$
R_{t}=\mu_{i, t}+\sigma_{i . t} \varepsilon_{t}
$$

where $E\left(R_{t} \mid \Phi_{t-1}\right)=\mu_{i, t}$, is the mean return and $\sigma_{i, t}$ is the standard deviation. In this model, the conditional mean return $\mu_{i, t}$ and variance $\sigma_{i, t}^{2}$ at time $t$ depend on the market regime at time $t\left(\right.$ i.e., $\left.S_{t}=i\right)$ and may be time-varying. The explicit parameterization of the conditional mean process should depend on the data. Furthermore, the conditional variance can be modeled as an autoregressive process, and the conditional density function of the latent innovations, $\varepsilon_{t}$, is assumed to be Gaussian, that is $\varepsilon_{t} \mid \Phi_{t-1} \sim N\left(0, \sigma_{i, t}^{2}\right)$. Finally, the most common approach used in the literature is followed by considering a constant matrix of transition or switching probabilities $\Pi$ given by: ${ }^{4}$

4. A model with time-varying transition probabilities is not used herein since the 


$$
\Pi=\left[\begin{array}{cccc}
\pi_{1,1} & \pi_{1,2} & \cdots & \pi_{1, N} \\
\pi_{2,1} & \pi_{2,2} & \cdots & \pi_{2, N} \\
\vdots & \vdots & \vdots & \vdots \\
\pi_{N, 1} & \pi_{N, 2} & \cdots & \pi_{N, N}
\end{array}\right]
$$

where $\pi_{i, j}=\operatorname{prob}\left(S_{t}=j \mid S_{t-i}=i\right) ; \quad \sum_{j=1}^{n} \pi_{i, j}=1 \forall j ; \quad 0 \leq \pi_{i, j} \leq 1 \forall i, j$.

\section{B. Two-Regime Switching Model for Emerging Market Returns}

The general model is restricted to a two-regime switching model since there is no a priori evidence of more than two regimes in emerging stock markets. To test for the regime-switching in these markets, it is postulated that returns from a given emerging market, $R_{t}$, are drawn from a distribution with constant mean $\mu$ and standard deviation $\sigma$ if there is no switching in regime. That is $\mu_{1}=\mu_{2}=\mu$ and $\sigma_{1}=\sigma_{2}=\sigma$, so that the no-switching model or the Single-Regime Model (SRM) is stated as:

$$
R_{t}=\mu+\sigma \varepsilon_{t} .
$$

Three alternative models are examined with switching in market regimes. The binary regime variable, $S_{t}$, takes on the value of 1 when the market is in regime 1 and 2 when the market is in regime 2 . In the first regime, returns are drawn from a distribution with constant mean $\mu_{1}$ and standard deviation $\sigma_{1}$, while, in the second regime, they are drawn from a distribution with mean $\mu_{2}$ and standard deviation $\sigma_{2}$. Each regime may be characterized by a different mean returns, a different volatility, or both different mean and volatility. Therefore, the first alternative specification is the General Switching Model (GSM)

eligible conditioning variables in the information set are limited. They must be independent of the contemporaneous realization of the regime (Gray [1997]). Note that this condition is not met in most of the models presented in the literature. Diebold et al. (1995), Bekaert and Harvey (1995), and Schaller and van Norden (1997) are some examples where the switching probabilities are modeled as a function of some exogenous conditioning variables. 
formulated as follows:

$$
R_{t} \mid \Phi_{t-1}= \begin{cases}\mu_{1}+\sigma_{1} \varepsilon_{t} & \text { with probabilitiy } p_{1, t} \\ \mu_{2}+\sigma_{2} \varepsilon_{t} & \text { with probability } p_{2, t}=\left(1-p_{1, t}\right)\end{cases}
$$

In this model, returns are assumed to be drawn from two distributions with different means and variances. The conditional probability of being in regime 1 at time t, $p_{1, t}=\operatorname{prob}\left(S_{t}=1 \mid \Phi_{t-1}\right)$, is inferred from the return series using the following recursive representation: ${ }^{5}$

$$
\begin{aligned}
p_{1, t} & =\pi_{1,1}\left[\frac{g_{1, t-1} p_{1, t-1}}{g_{1, t-1} p_{1, t-1}+g_{2, t-1}\left(1-p_{1, t-1}\right)}\right] \\
& +\left(1-\pi_{2,2}\right)\left[\frac{g_{2, t-1}\left(1-p_{1, t-1}\right)}{g_{1, t-1} p_{1, t-1}+g_{2, t-1}\left(1-p_{1, t-1}\right)}\right],
\end{aligned}
$$

where $g_{1, t}=f\left(R_{t} \mid S_{t}=1\right), g_{2, t}=f\left(R_{t} \mid S_{t}=2\right), f$ is the density probability function of $R_{t}$ conditional on available information, and the $\pi_{i, j}=\operatorname{prob}\left(S_{t}=j \mid S_{t-1}=i\right)$ are the transition probabilities. The terms in brackets in equation 6 are the filter probabilities at time $t-1$ and represent respectively $\operatorname{prob}\left(S_{t}=1 \mid \Phi_{t-1}\right)$ and $=\operatorname{prob}\left(S_{t}=2 \mid \Phi_{t-1}\right)$.

The second alternative is a Volatility-Switching Model (VSM), which assumes that the two regimes differ only in terms of market volatility, the mean return remaining the same whatever the regime, i.e.,

$$
R_{t} \mid \Phi_{t-1}= \begin{cases}\mu+\sigma_{1} \varepsilon_{t} & \text { with probabilitiy } p_{1, t} \\ \mu+\sigma_{2} \varepsilon_{t} & \text { with probability } p_{2, t}=\left(1-p_{1, t}\right) .\end{cases}
$$

The third alternative is a Mean-Switching Model (MSM), which assumes that returns are drawn from two distributions with different

5. See Gray (1997) and Hamilton (1994) for details. 
TABLE 2. Test for Regime-switching in Emerging Markets (U.S. dollar returns)

\begin{tabular}{|c|c|c|c|c|c|c|c|c|c|}
\hline & Argentina & Brazil & Chile & Greece & India & Korea & Mexico & Thailand & Zimbabwe \\
\hline \multicolumn{10}{|c|}{ A. Log likelihood } \\
\hline SRM & -25.84 & 107.01 & 218.38 & 242.34 & 292.41 & 250.75 & 177.09 & 274.08 & 230.74 \\
\hline GSM & 47.83 & 127.27 & 240.48 & 292.91 & 313.92 & 270.40 & 208.37 & 302.23 & 242.51 \\
\hline VSM & 42.05 & 126.13 & 238.02 & 290.61 & 313.82 & 269.57 & 207.58 & 301.92 & 242.27 \\
\hline MSM & 25.57 & 120.11 & 223.24 & 283.04 & 308.15 & 265.22 & 199.38 & 283.95 & 239.57 \\
\hline \multicolumn{10}{|c|}{ B. Likelihood ratio: GSM, VSM, and MSM against the null of no-switching } \\
\hline GSM & 147.35 & 40.51 & 44.19 & 101.14 & 43.02 & 39.29 & 62.56 & 56.30 & 23.53 \\
\hline VSM & 135.79 & 38.23 & 39.27 & 96.56 & 42.83 & 37.63 & 60.98 & 55.68 & 23.04 \\
\hline MSM & 102.83 & 26.19 & 9.71 & 81.40 & 31.48 & 28.94 & 44.58 & 19.75 & 17.64 \\
\hline
\end{tabular}

C. Likelihood ratio: General Switching Model against the VSM and MSM

\begin{tabular}{lccccccccc} 
VSM & 11.56 & 2.28 & 4.92 & 4.58 & .19 & 1.67 & 1.58 & .62 & .49 \\
(p-value) & $(.001)$ & $(.131)$ & $(.027)$ & $(.032)$ & $(.663)$ & $(.197)$ & $(.208)$ & $(.431)$ & $(.483)$ \\
MSM & 44.52 & 14.32 & 34.48 & 19.74 & 11.54 & 10.36 & 17.98 & 36.56 & 5.89 \\
(p-value) & $(.000)$ & $(.000)$ & $(.000)$ & $(.000)$ & $(.001)$ & $(.001)$ & $(.000)$ & $(.000)$ & $(.015)$ \\
\hline
\end{tabular}




\section{TABLE 2. (Continued)}

Ljung-Box statistics for serial correlation of the squared standardized residuals from the single regime model (SRM)

\begin{tabular}{lccccccccc}
$L B_{1}$ & 1.915 & 4.411 & .404 & .002 & 17.437 & 5.993 & 29.119 & 2.143 & 2.397 \\
$(\mathrm{p}-$ value $)$ & $(.167)$ & $(.036)$ & $(.525)$ & $(.961)$ & $(.000)$ & $(.014)$ & $(.000)$ & $(.143)$ & $(.122)$ \\
$L B_{6}$ & 16.821 & 13.195 & 6.282 & 26.890 & 44.387 & 13.203 & 68.183 & 46.221 & 11.559 \\
$(\mathrm{p}-$ value $)$ & $(.010)$ & $(.040)$ & $(.392)$ & $(.000)$ & $(.000)$ & $(.040)$ & $(.000)$ & $(.000)$ & $(.073)$ \\
$L B_{12}$ & 18.213 & 56.800 & 35.896 & 55.791 & 53.045 & 15.778 & 71.359 & 49.596 & 14.792 \\
$(\mathrm{p}$-value $)$ & $(.109)$ & $(.000)$ & $(.000)$ & $(.000)$ & $(.000)$ & $(.202)$ & $(.000)$ & $(.000)$ & $(.253)$ \\
\hline
\end{tabular}

Note: Panel A reports the value of the log-likelihood function for each model. Panel B reports tests of the null hypothesis of no-switching in market returns (SRM) against the three alternatives of regime switching (i.e., GSM, VSM, and MSM). At the 5\% and 1\% significance level, the critical values are respectively 10.34 and 13.81 for switching in mean or in volatility, and 13.52 and 17.67 for switching in both mean and standard deviation. Pane C reports standard likelihood ratio tests for the null hypothesis of VSM and MSM against the alternative of switching in both means and volatility (GSM). The test statistics are chi-squared distributed with one degree of freedom. Panel D reports the Ljung-Box statistics for serial correlation of the squared standardized residuals from the Single Regime Model (SRM) out to $i$ lags $\left(L B_{i}\right)$ with their p-values in parentheses. 
means $\left(\mu_{1}\right.$ and $\left.\mu_{2}\right)$ but the same volatility $\sigma_{1}=\sigma_{2}=\sigma$, i.e.,

$$
R_{t} \mid \Phi_{t-1}= \begin{cases}\mu_{1}+\sigma \varepsilon_{t} & \text { with probabilitiy } p_{1, t} \\ \mu_{2}+\sigma \varepsilon_{t} & \text { with probability } p_{2, t}=\left(1-p_{1, t}\right) .\end{cases}
$$

It is important to note that, for the three alternative models, the regime probability $p_{i, t}$ varies through time while the transition probabilities are time-invariant. Given these specifications of the nature of regimeswitching in market returns, the next step is to test whether there is statistical evidence of regime-switching in the nine emerging markets.

\section{Evidence of Two Regimes in Emerging Market Returns}

In this section, whether there are at least two regimes in emerging market return series is formally tested. Each of the three alternative regime-switching models is tested against the null hypothesis of noregime switching. Since the transition probabilities are not defined under the null of no-switching, the asymptotic distributions of likelihood ratio, Lagrange multiplier or Wald test statistics are nonstandard. To determine whether there is statistically significant evidence of regime-switching, the likelihood ratio test presented by Hansen (1992) is used, where the transition probabilities are treated as nuisance parameters. Garcia (1998) tabulates critical values for this non-standard test statistic.

With dollar return series, the likelihood ratio tests of the null hypothesis of no-switching against the three alternative specifications are presented in panel B of table 2. The results indicate a strong rejection of the null hypothesis of no-switching (the SRM) when the alternative is a switching in both mean and volatility (the GSM) for all nine emerging markets. In fact, the $1 \%$ critical value for the likelihood ratio statistic in this case is 17.67 while the estimated likelihood ratios range from 23.53 for Zimbabwe to 147.35 for Argentina. The tests also reject the null of no-switching when switching in volatility (VSM) is the alternative for all of the emerging markets. The $1 \%$ critical value for the likelihood ratio statistic in this case is 13.81 while the estimated likelihood ratios range from 23.04 for Zimbabwe to 135.79 for Argentina. The hypothesis of no-switching in the distribution of emerging market returns is also rejected against the alternative of 
TABLE 3. Test for Regime-Switching in Emerging Markets (Returns in Local Currencies)

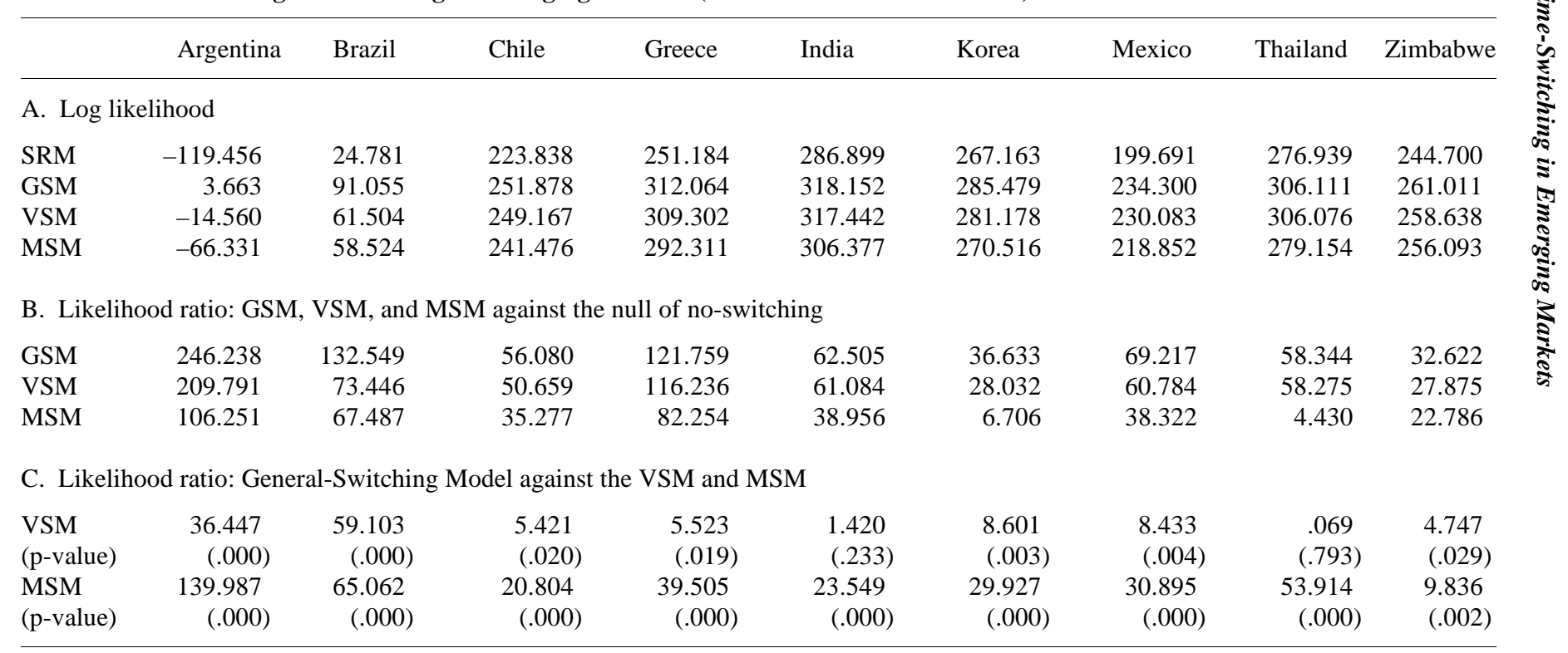

Note: All variables are as defined in table 2. 
switching in means (MSM) for all markets except for Chile. ${ }^{6}$ With local currency data, the results presented in panel B of table 3 confirm those obtained with dollar return series. These results show strong evidence that, whatever the specification of the nature of switching, the null of no-switching is rejected for almost allof the emerging markets.

The restrictions imposed by the volatility regime-switching model where $\mu_{1}=\mu_{2}$, and the mean regime-switching model where $\sigma_{1}=\sigma_{2}$ on the unrestricted general-switching model $\left(\mu_{1} \neq \mu_{2}\right.$ and $\left.\sigma_{1} \neq \sigma_{2}\right)$, are tested. Panel $\mathrm{C}$ of table 2 (dollar return series) and table 3 (local currency series) reports standard likelihood ratio statistics, distributed as chi-squared with one degree of freedom, for these tests. At the $1 \%$ critical level, the results based on dollar return series show that the null hypothesis of volatility switching (VSM) is only rejected for Argentina when the alternative is the GSM. The result for Argentina may be driven at least in part by the fact that this country passed through a period of high turbulence (inflation, budget deficits, over-regulated economy) prior to the Convertibility Act in 1991 that marked a permanent change in Argentina. Following this act, the Argentine government took many other economic actions (e.g., more deregulation of the economy, privatization, liberalization, etc.) that reinforced its commitment to price stability and economic growth. These changes resulted in more stability with more credibility and less volatility that command fewer returns in the Argentine stock market. Therefore, the regime-switching in Argentina is better characterized by a simultaneous switch in mean and volatility. The VSM is also rejected for Chile and Greece when the alternative is the GSM at the 5\% level. On the other hand, with local currency return series, the null hypothesis of volatility switching (VSM) is rejected for Argentina, Brazil, Chile, Greece, Korea, Mexico, and Zimbabwe (at the 5\% critical level) when the alternative is the GSM. Whether the data are in local currencies or in U.S. dollars, the hypothesis of switching in mean (MSM) is rejected for all emerging stock markets when the alternative is a switch in both the mean returns and the volatility (GSM).

It is very interesting to note that, at the $5 \%$ critical level, the VSM

6. Since the results also show a strong rejection of the null of no-switching when the alternative is switching in both the mean return and the volatility (GSM) or in volatility only (VSM) for Chile, one can conclude that the regime-switching behavior of the Chilean stock market might be highly driven by switches in volatility rather than switches in mean returns. 
hypothesis is rejected for all emerging markets but India and Thailand when local currency data are used and the alternative is the GSM. However, with dollar return series, the VSM is only rejected for Argentina, Chile, and Greece. These results suggest that when emerging markets returns are subject to switches in both mean and volatility in local currency terms (seven of the nine emerging markets returns are better characterized by GSM), the distribution of emerging market dollar returns evolves through two regimes that are different mainly in terms of volatility (six of the nine emerging markets returns are better characterized by VSM). These results have important implications for the emerging markets. Seeing that the distribution of returns is not the same for foreign and for domestic investors, their rational behavior should be different. In fact, since the returngenerating process is characterized by a constant expected return but can shift periodically from low volatility to high volatility state, foreign investors are not fully rewarded for the risk they bear in the highvolatility regime, or they are over-rewarded in the low-volatility regime. These results confirm those of Bekaert (1995) and Harvey (1995), but only for foreign investors and in a specific market regime. Therefore, based on foreign investors' assessment of the ex ante probability of high volatility regime, it may be rational to periodically observe capital inflows and outflows from the emerging markets. Restrictions imposed by some governments on foreign ownership and trading (an example is a minimum holding period) and high transaction costs contribute to the reduction of these flows.

\section{Estimation of Switching Models in Emerging Markets}

For the three regime-switching models, parameters are estimated by maximizing the conditional log-likelihood function that is evaluated recursively using Hamilton's (1994) updating formula. All models are estimated using the GAUSS MAXLIK and CML modules. An EM algorithm is used first to get good starting values, which are then passed to MAXLIK for final convergence. ${ }^{7}$ Since the results are not materially

7. The Bank of Canada Gauss procedures written by Simon van Norden, Jeff Gable, and Robert Vigfusson, as well as the Gauss code written by Stephen Gray, are used for the estimation. 
TABLE 4. Parameter Estimates of the General Regime-Switching Model (GSM)

\begin{tabular}{|c|c|c|c|c|c|c|c|c|c|c|}
\hline & $\mu_{1}$ & $\mu_{2}$ & $\sigma_{1}$ & $\sigma_{2}$ & $\pi_{1,1}$ & $\pi_{2,2}$ & $L B_{1}$ & $L B_{6}$ & $L B_{12}$ & $L F$ \\
\hline \multirow[t]{2}{*}{ Argentina } & -.0027 & .287 & .1372 & .5029 & .923 & .635 & .004 & 1.927 & 4.024 & 47.8 \\
\hline & $(.010)$ & $(.086)$ & $(.009)$ & $(.057)$ & $(.028)$ & $(.113)$ & $(.95)$ & $(.93)$ & $(.98)$ & \\
\hline \multirow{2}{*}{ Brazil } & .0019 & .0265 & .0644 & .1805 & .9529 & .9853 & .800 & 3.241 & 25.65 & 127.3 \\
\hline & $(.009)$ & $(.013)$ & $(.007)$ & $(.008)$ & $(.042)$ & $(.011)$ & $(.37)$ & $(.78)$ & $(.01)$ & \\
\hline \multirow[t]{2}{*}{ Chile } & .0139 & .1007 & .0838 & .1676 & .9883 & .9470 & .321 & 1.951 & 13.94 & 240.5 \\
\hline & $(.006)$ & $(.039)$ & $(.005)$ & $(.020)$ & $(.011)$ & $(.044)$ & $(.57)$ & $(.92)$ & $(.30)$ & \\
\hline \multirow[t]{2}{*}{ Greece } & -.0029 & .0668 & .0642 & .1860 & .9867 & .9233 & .676 & 4.566 & 21.02 & 292.9 \\
\hline & $(.005)$ & $(.035)$ & $(.003)$ & $(.031)$ & $(.010)$ & $(.042)$ & $(.41)$ & $(.60)$ & $(.05)$ & \\
\hline \multirow[t]{2}{*}{ India } & .0063 & .0193 & .0457 & .1028 & .9492 & .9453 & 2.446 & 10.70 & 14.10 & 313.8 \\
\hline & $(.005)$ & $(.010)$ & $(.005)$ & $(.007)$ & $(.028)$ & $(.031)$ & $(.12)$ & $(.10)$ & $(.29)$ & \\
\hline \multirow[t]{2}{*}{ Korea } & -.0016 & .0392 & .0632 & .1439 & .8930 & .6845 & .169 & 1.629 & 5.39 & 270.4 \\
\hline & $(.006)$ & $(.025)$ & $(.006)$ & $(.016)$ & $(.056)$ & $(.132)$ & $(.68)$ & $(.95)$ & (.94) & \\
\hline
\end{tabular}


TABLE 4. (Continued)

\begin{tabular}{llccccccccc}
\hline Mexico & -.0250 & .0305 & .2323 & .0863 & .8258 & .9667 & 1.021 & 3.164 & 13.49 & 208.4 \\
& $(.039)$ & $(.006)$ & $(.038)$ & $(.005)$ & $(.111)$ & $(.019)$ & $(.31)$ & $(.79)$ & $(.33)$ & 7.91 \\
Thailand & -.0059 & .0145 & .1517 & .0591 & .8687 & .9649 & .220 & 4.579 & 302.0 \\
& $(.022)$ & $(.005)$ & $(.020)$ & $(.004)$ & $(.081)$ & $(.019)$ & $(.64)$ & $(.60)$ & $(.79)$ & \\
Zimbabwe & -.0420 & .0408 & .1069 & .0834 & .9611 & .9703 & .223 & 9.245 & 12.26 & 242.5 \\
& $(.016)$ & $(.009)$ & $(.008)$ & $(.004)$ & $(.031)$ & $(.023)$ & $(.64)$ & $(.16)$ & $(.43)$ & \\
\hline
\end{tabular}

Note: $R_{t} \mid \Phi_{t-1}=\mu_{1}+\sigma_{1} \varepsilon_{t}$ with probability of $p_{1, t}$, or $R_{t} \mid \Phi_{t-1}=\mu_{2}+\sigma_{2} \varepsilon_{t}$ with probability of $p_{2, t}=\left(1-p_{1, t}\right)$, where $p_{1, t}$ is defined by equation 6 . Estimates are based on a sample of monthly market returns reported in U.S. dollars from January 1976 to December 1997. The average duration of each regime is $\left(1-\pi_{i j}\right)^{-1} . L B_{i}$ denotes the Ljung-Box statistic for serial correlation of the squared standardized residuals out to $i$ lags. $L F$ is the maximum of loglikelihood function. Standard errors (for parameter estimates) and p-values (for Ljung-Box statistics) are in parentheses. 
different with local currency data, only results based on dollar returns are reported.

\section{A. Parameter Estimates of GSM, VSM and MSM}

Table 4 presents parameter estimates of the general regime-switching model (GSM) in which emerging stock market returns are assumed to be drawn from two distributions which differ both in their means and their standard deviations. The regimes are characterized by $\mu_{1}<\mu_{2}$. In regime 1 , the mean returns are negative for six out of the nine emerging markets but are not significantly different from zero except for Zimbabwe. For the three other markets where the mean returns are positive (i.e., Brazil, Chile, and India), only the Chile market shows statistically significant mean returns in regime 1 . On the other hand, mean returns in regime 2 are all positive and significantly different from zero (at the $10 \%$ critical level) except for South Korea. It is important to note the large difference in mean returns between the two regimes. Except for Mexico, Thailand, and Zimbabwe, where the volatility in regime 1 (low mean-returns regime) is higher than the volatility in regime 2, the estimates of $\sigma_{1}$ and $\sigma_{2}$ show that the volatility in regime 2 (high mean-returns regime) is at least twice the volatility in regime 1 for the other six emerging markets. The estimates of the transition probabilities show that the two regimes are quite persistent. The average expected durations range from 5.7 months in Mexico to 85.5 months in Chile for regime 1 and from 2.7 months in Argentina to 68 months in Brazil for regime 2. Note that when Turner et al. (1989) examined U.S. stock market returns from January 1946 to December 1987, they found that the average lengths of low-variance and of highvariance episodes were 97.7 months and 3.8 months, respectively.

Table 5 presents the parameter estimates of the Volatility-Switching Model where regimes are identified by $\sigma_{1}<\sigma_{2}$. The estimates of mean returns are all positive, except for Greece, which has a negative but insignificant mean return. The estimates are quite different from those obtained in table 1 , where a constant mean and standard deviation is assumed. The distribution of Argentina stock market returns clearly illustrates this point. A single-regime model reveals a monthly mean return of $4.76 \%$ with a standard deviation of $26.74 \%$, while the VSM shows that the mean return is just $.51 \%$ with standard deviation of $13.58 \%$ in regime 1 and $56.61 \%$ in regime 2 . For all emerging markets, the volatility of returns in regime 2 is about twice or even three times 
TABLE 5. Parameter Estimates of the Volatility Switching Model (VSM)

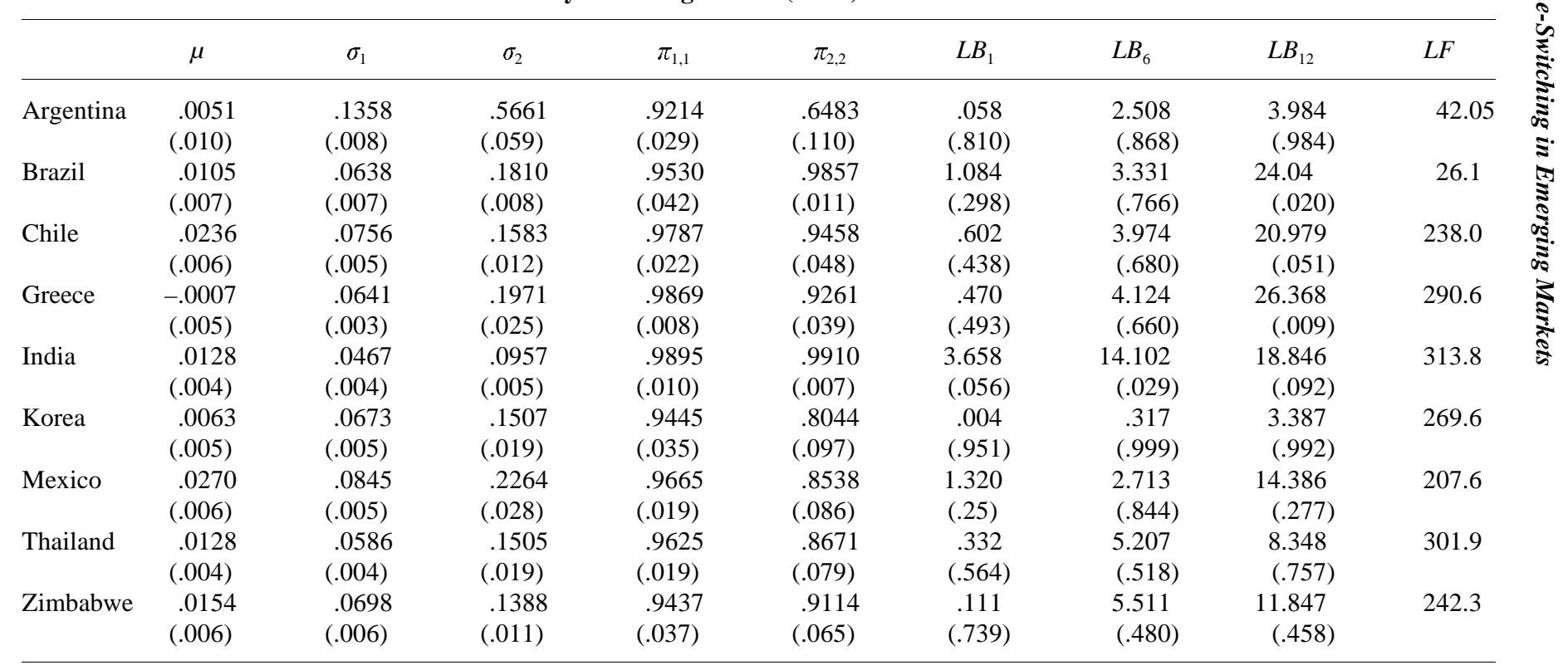

Note: $R_{t} \mid \Phi_{t-1}=\mu+\sigma_{1} \varepsilon_{t}$ with probability of $p_{1, t}$ or $R_{t} \mid \Phi_{t-1}=\mu+\sigma_{2} \varepsilon_{t}$ with probability of $p_{2, t}=\left(1-p_{1, t}\right)$. All variables are as defined in table 4 . 
TABLE 6. Parameter Estimates of the Mean Switching Model (MSM)

\begin{tabular}{|c|c|c|c|c|c|c|c|c|c|}
\hline & $\mu_{1}$ & $\mu_{2}$ & $\sigma$ & $\pi_{1,1}$ & $\pi_{2,2}$ & $L B_{1}$ & $L B_{6}$ & $L B_{12}$ & $L F$ \\
\hline \multirow[t]{2}{*}{ Argentina } & .0128 & 1.0490 & .1913 & .9652 & .0001 & 8.285 & 23.612 & 25.066 & 25.6 \\
\hline & $(.013)$ & $(.045)$ & $(.006)$ & $(.012)$ & $(.000)$ & $(.004)$ & $(.000)$ & $(.015)$ & \\
\hline \multirow{2}{*}{ Brazil } & -.0076 & .3666 & .1275 & .9398 & .2633 & .702 & 9.356 & 43.275 & 120.1 \\
\hline & $(.010)$ & $(.057)$ & $(.005)$ & $(.023)$ & $(.118)$ & $(.402)$ & $(.155)$ & $(.000)$ & \\
\hline \multirow[t]{2}{*}{ Chile } & -.0148 & .0494 & .1010 & .9721 & .9863 & .430 & 8.771 & 38.105 & 223.2 \\
\hline & $(.019)$ & $(.011)$ & $(.003)$ & $(.044)$ & $(.018)$ & $(.512)$ & $(.187)$ & $(.000)$ & \\
\hline \multirow[t]{2}{*}{ Greece } & -.0034 & .3755 & .0728 & .9728 & .0931 & .041 & 27.279 & 58.5 & 283.0 \\
\hline & $(.005)$ & $(.020)$ & $(.003)$ & $(.011)$ & $(.130)$ & $(.840)$ & $(.000)$ & $(.000)$ & \\
\hline \multirow[t]{2}{*}{ India } & .0017 & .1952 & .0656 & .9645 & .3911 & .211 & 14.666 & 23.049 & 308.1 \\
\hline & $(.005)$ & $(.022)$ & $(.003)$ & $(.016)$ & $(.151)$ & $(.696)$ & $(.023)$ & $(.027)$ & \\
\hline \multirow[t]{2}{*}{ Korea } & -.2953 & .0124 & .0862 & .999 & .9962 & .134 & .837 & 2.102 & 265.2 \\
\hline & $(.171)$ & $(.006)$ & $(.003)$ & $(.000)$ & $(.006)$ & $(.715)$ & $(.991)$ & $(.999)$ & \\
\hline \multirow[t]{2}{*}{ Mexico } & -.3482 & .0349 & .1021 & .4351 & .9796 & 6.740 & 35.358 & 42.505 & 199.4 \\
\hline & $(.031)$ & $(.007)$ & $(.004)$ & $(.184)$ & $(.010)$ & (.009) & $(.000)$ & $(.000)$ & \\
\hline \multirow[t]{2}{*}{ Thailand } & -.0995 & .0184 & .0806 & .9842 & .9959 & 5.163 & 19.095 & 21.518 & 284.0 \\
\hline & $(.019)$ & $(.006)$ & $(.003)$ & $(.067)$ & $(.004)$ & $(.023)$ & $(.004)$ & $(.043)$ & \\
\hline \multirow[t]{2}{*}{ Zimbabwe } & -.0455 & .0397 & .0926 & .9539 & .9693 & 1.751 & 10.939 & 14.603 & 239.6 \\
\hline & $(.012)$ & $(.011)$ & $(.004)$ & $(.032)$ & $(.026)$ & $(.186)$ & (.090) & $(.264)$ & \\
\hline
\end{tabular}

Note: $R_{t} \mid \Phi_{t-1}=\mu_{1}+\sigma_{1} \hat{\varepsilon}_{t}$ with probability of $p_{1, t}$, or $R_{t} \mid \Phi_{t-1}=\mu_{2}+\sigma_{2} \varepsilon_{t}$ with probability of $p_{2, t}=\left(1-p_{1, t}\right)$. All variables are as defined in table 4 
the volatility of returns in regime 1 . The estimates of transition probabilities show that the low-volatility regime is more persistent than the high-volatility regime for all emerging markets except for Brazil and India.

The parameter estimates of the Mean-Switching Model (MSM) are presented in table 6 . Keeping the volatility constant across regimes, the results presented in table 5 show the enormous difference in mean returns between the two regimes. For Argentina, Brazil, Greece, and India, the mean returns in regime 2 are very high, but this high return regime does not persist when it occurs. In fact, for these countries, the average durations for the high-return regime range from one month for Argentina to 1.6 months for India. On the other hand, the low-return regime is very persistent for all emerging markets except for Mexico, where monthly stock returns drop from $3.49 \%$ to $-34.82 \%$ when regime 1 occurs. The average duration of this low-return state is 1.77 months for Mexico. South Korean market returns also show the same pattern as Mexico, except that the low-return regime is more persistent. The high degree of persistence of the low-return regime in South Korea reflects the impact of the recent Asian crisis from the middle of 1997 until the end of our sample period. It is important to recall that the MSM is rejected when the alternative is the GSM for almost all of the emerging markets.

\section{B. Dating Regime-switching in Emerging Market Returns}

In addition to the regime-switching probabilities or the probabilities of persistence of each regime, there are two conditional probabilities that are very important when dealing with the Markov regime-switching models. The first, called the smoothed probability, is based on the entire data set and used to access when a switch in regime has occurred, i.e. $\operatorname{prob}\left(S_{t}=i \mid \Phi_{T}\right)$. The second, called the ex ante probability, is especially of interest for portfolio managers in forecasting the future regime based on information that is currently available, i.e. $\operatorname{prob}\left(S_{t}=i \mid \Phi_{t-1}\right)$. The ex ante probability series are constructed (equation 6) when estimating parameters of each model. The Gray's (1997) recursive procedure (smoothing filter) is used to convert ex ante probabilities to smoothed probabilities. 

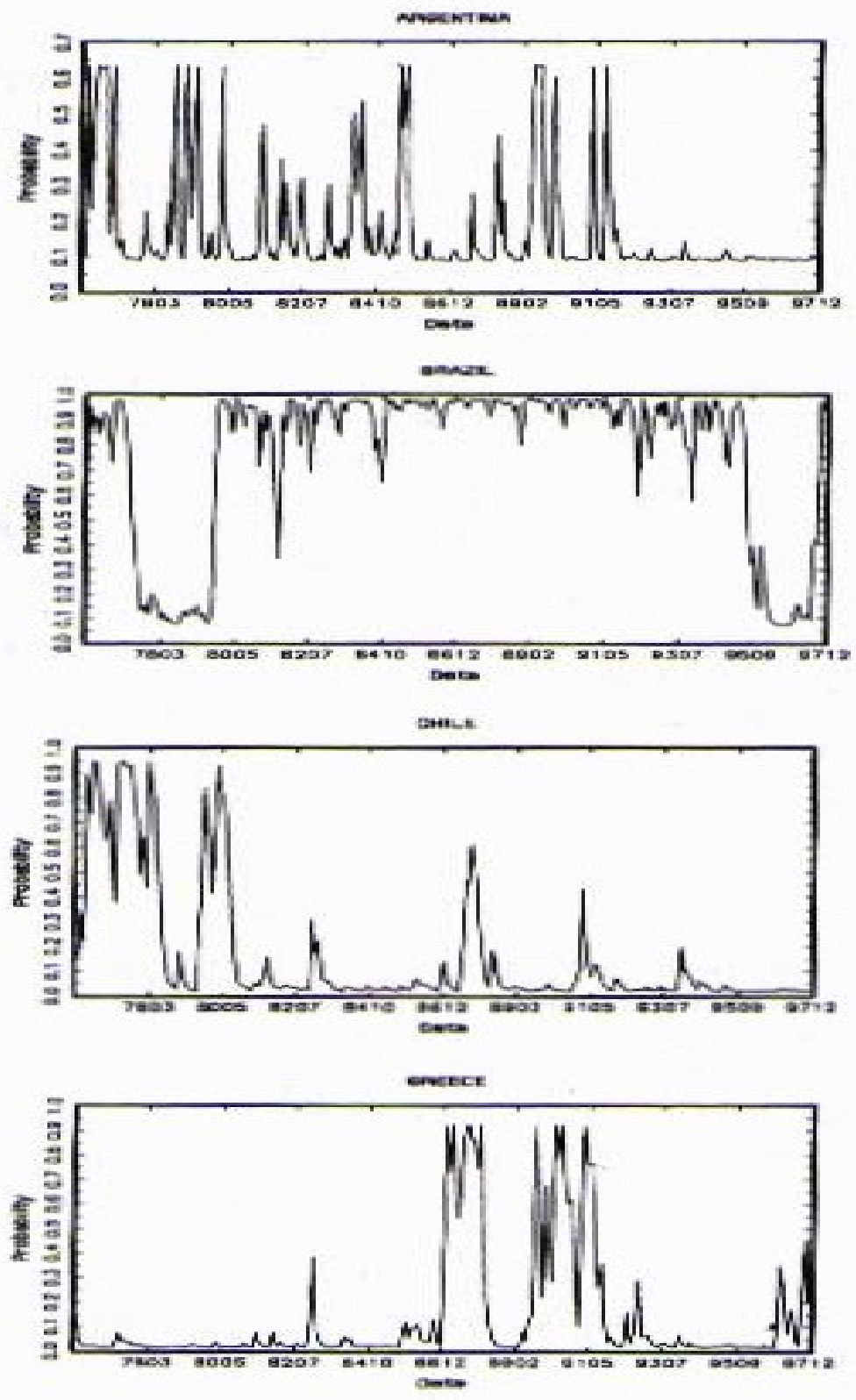

FIGURE 1.-(Continued) 

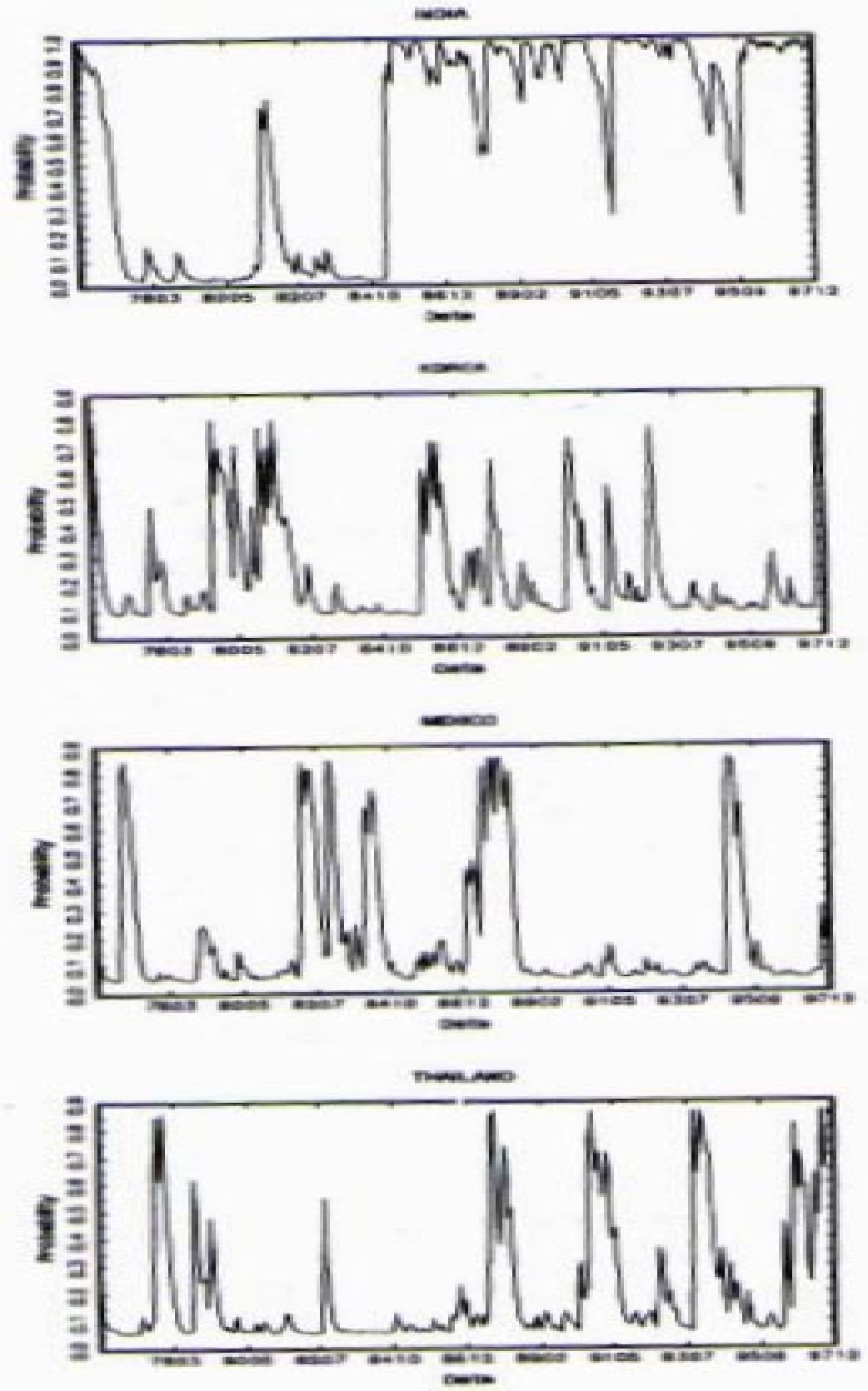

FIGURE 1.-(Continued) 


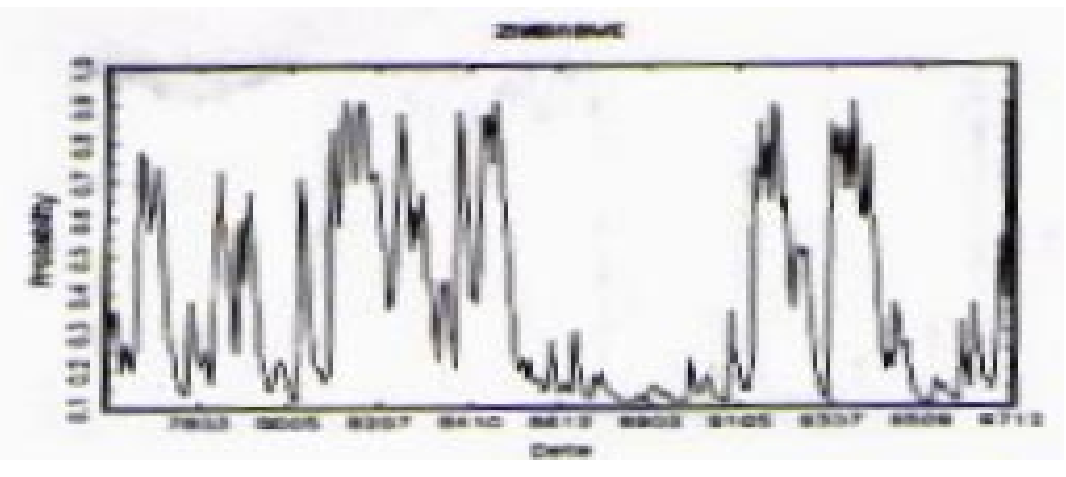

Figure 1.-Ex Ante Regime. The ex ante probability of regime 2, $\operatorname{prob}\left(S_{t}=2 \mid \Phi_{t-1}\right)$, is plotted based on the best fitted model for each country, i.e., the GSM for Argentina, Chile and Greece, and the VSM for the other markets. Tables 4-6 provide information on the return distribution in regime 2 for each market. Results are based on U.S. dollar return series

For the nine emerging markets studied herein, the smoothed probability closely mirrors the ex ante probability. Periods when the ex ante probability of a given regime is highest end with a spike in the smoothed probability. Therefore, only the ex ante probabilities of regime 2 for each market are reported in figure 1 using the best fitted model according to the LR test, that is the GSM for Argentina, Chile, and Greece and the VSM for the other markets. For many emerging markets, the ex ante probabilities of regime 2 with the VSM are not materially different from those obtained with the GSM. ${ }^{8}$ In other words, the regime-switching documented in the GSM can be primarily attributed to the switching in volatility. This result supports our previous finding from the likelihood ratio tests suggesting that the VSM cannot be rejected when the GSM is the alternative for most of the emerging markets when returns are expressed in U.S. dollars.

Figure 1 shows no common patterns in the regime-switching dates among the emerging markets. The only exception is around October 87,

8. The figures which illustrate the ex ante and smoothed probabilities obtained with the GSM, the VSM, and the MSM for the nine emerging markets (local currencies and U.S. dollar returns) are available and can be obtained from the author upon request. 
when there was an increase in the probability of the high-volatility regime in all the emerging markets which, until then, had been in the low-volatility regime. Other switches from low-to high-volatility regime seem to be more specific to each market. For example, Argentina which experienced a series of switches between regime 1 and 2 during the $70 \mathrm{~s}$ and 80s with rampant inflation, chronic budget deficits, and an overregulated economy - has been displaying a very low probability of regime 2 (regime with high mean return and high volatility) since the Convertibility Act in 1991. For Mexico, the ex ante probability of regime 1 (negative mean return and high volatility) was very high during the periods 1976, 1981-1984, and 1987-1988, and in late 1994. These periods correspond to the debt crisis (1981-1984) and especially to collapses of the Mexican exchange rate regime: $39 \%$ devaluation of peso against U.S. dollar in September 1976, 47\% devaluation in December 1982, crawling peg with several modifications of the crawl rate in 1982 and 1984, floating of the peso in the late 1987, and peso devaluation followed by its floating in late 1994. Except for the peso devaluation transition period (1994-1995), the Mexican stock market has remained in a low-volatility regime since early 1989 when most barriers of foreign investments were removed. ${ }^{9}$ For Thailand and Korea, figure 1 shows frequent shifts from one regime to the other, and a kind of two- or three-year cycle can be observed from the distribution of the shifts in the South Korean stock market. Moreover, the probability of high-volatility regime increases substantially in 1996 and 1997 for these markets, reflecting the Asian financial crisis. It is also interesting to note that the regime-switching dates based on the dollar return series and their best-fitted models are almost always similar to those obtained with local currency returns.

\section{Diagnostic Tests}

The results presented in table 2 (panel D) show that the squared standardized residuals from the single-regime model (SRM) are highly serially correlated as evidenced by the highly significant Ljung-Box statistics. In other words, the single regime-model does a poor job of modeling volatility in emerging markets. The last column of table 4, 5 ,

9. From 1989, 100\% foreign investments in most firms are possible, except for some key sectors (e.g., the $30 \%$ limit in the banking industry). 


\begin{tabular}{|c|c|c|c|c|c|c|c|c|c|}
\hline & Argentina & Brazil & Chile & Greece & India & Korea & Mexico & Thailand & Zimbabब्ब \\
\hline \multicolumn{9}{|c|}{ A. General Regime-switching Model (GSM) } & $\stackrel{s}{=}$ \\
\hline Regression 1: $\mathrm{R}^{2}$ & .035 & .047 & .038 & .071 & .061 & .023 & .105 & .084 & .018 \\
\hline Regression 2: $\mathrm{R}^{2}$ & .042 & .058 & .092 & .137 & .090 & .041 & .172 & .127 & .039 \\
\hline \multicolumn{9}{|c|}{ B. Volatility Switching Model (VSM) } & 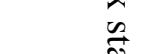 \\
\hline Regression 1: $\mathrm{R}^{2}$ & .025 & .044 & .047 & .041 & .056 & .029 & .102 & .090 & .04. \\
\hline Regression 2: $\mathrm{R}^{2}$ & .037 & .056 & .079 & .106 & .121 & .046 & .162 & .130 & .095. \\
\hline F-Statistic & .519 & .530 & 1.448 & 3.029 & 3.081 & .742 & 2.983 & 1.916 & 2.118 \\
\hline Regression $2: \mathrm{R}^{2}$ & .039 & .028 & .039 & .133 & .170 & .017 & .107 & .071 & $.03 \frac{9}{9}$ \\
\hline F-Statistic & 1.691 & 1.115 & 1.431 & 6.344 & 4.970 & .678 & 1.633 & 1.480 & $.69 \frac{9}{2}$ \\
\hline Significance level & .124 & .354 & .203 & .000 & .000 & .668 & .138 & .185 & .65. \\
\hline
\end{tabular}


Regime-Switching in Emerging Markets 
squared standardized residuals out to 1, 6, and 12 lags for the GSM, the VSM, and the MSM, respectively. The results show unambiguously a significant reduction of the Ljung-Box statistics for the three specifications of the regime-switching model. Therefore, allowing regime-switching in emerging markets returns help to capture their stochastic volatility.

As suggested by Garcia and Perron (1996), two regressions are run to assess the presence of any remaining ARCH effects once the shifts in mean and variance have been taken into account. First, the squared residuals are projected on the ex ante probabilities of regime 2 . Then, the independent variables in the previous regression are expanded by including six lagged squared residuals. The results for these regressions for the GSM, the VSM, and the MSM are presented in table 7, along with an $F$-statistic to test for the joint significance of the lagged squared residuals. The results show that, at the $1 \%$ level, the absence of any remaining ARCH effects cannot be rejected for seven out of the nine emerging markets once the shifts in both mean and variance (GSM) are taken into account. For Greece and Mexico, the hypothesis of the absence of remaining ARCH effects is rejected, suggesting the need to investigate a kind of GARCH regime-switching model for these markets. The results are about the same with the Volatility-Switching Model (panel B of table 7) and the Mean-Switching Model (panel C of table 7) except that, in addition to Greece and Mexico, an absence of remaining ARCH effects is rejected for India. The Ljung-Box statistics reported in tables 4,5 , and 6 also reveal dynamic behavior beyond that captured by the three regime-switching models, suggesting the need to incorporate additional dynamic features such as conditional mean or variance into these models.

\section{Conclusion}

Harvey (1995) and Bekaert (1995) find that higher systematic risks are associated with lower expected returns in many emerging markets. Ignoring the problems related to the estimation of systematic risks (assumptions about the market factors, domestic or international), this article shows that emerging markets go through two regimes whether the market returns are expressed in local currencies or in U.S. dollars. 
For domestic investors (returns in local currencies), the market evolves through two regimes with different mean returns and standard deviations (GSM), and the returns are proportional to the volatility. However, for foreign investors (dollar returns), each regime is different from the other, mainly with respect to the market's volatility: The Volatility Switching Model seems to outperform the GSM. Therefore, our results suggest that there is a regime in most emerging markets where the expected return is not proportional to the risk taken by foreign investors who express their return in U.S. dollars. When the ex ante probability of this regime is high, foreign investors would try to go out of the market. These results may explain the numerous booms and bursts in most of emerging stock markets (Williamson, 1993), the huge capital inflows followed by a mass redemption from the emerging markets by foreign investors (Howell, 1993). Switching between regimes seems to be associated with country-specific events such as monetary shocks and productivity switches that lead to fluctuating confidence in emerging stock markets. This study can be extended to investigate the specific fundamental variables (e.g., macro-economic, market-specific, or firm-specific variables) that can be used to predict transitions from one regime to another. At a theoretical level, there is a need for asset pricing models that account for the stylized facts that emerge from this article. The first-order regime-switching models considered herein do not account for all the ARCH effects in the emerging markets. For further understanding of emerging stock markets, a GARCH-regime-switching model should be investigated along with its relative performance in forecasting emerging market volatility compared with that of simple GARCH models.

\section{References}

Bekaert, G. 1995. Market integration and investment barriers in emerging equity markets. World Bank Economic Review 9 (1): 75-107.

Bekaert, G. and Harvey, C. R. 1995. Time-varying world market integration. Journal of Finance 50 (2): 403-444.

Bekaert, G. and Harvey, C. R. 1997. Emerging equity market volatility. Journal of Financial Economics 43 (1): 29-77.

Bekaert, G.; Erb, C. B.; Harvey C. R.; and Viskanta, T. E. 1998. Distributional characteristics of emerging market returns and asset allocation. Journal of 
Portfolio Management 24 (2): 101-116.

Bekaert, G.; Erb, C. B.; Harvey, C. R.; and Viskanta, T. E. 1997. What matters for emerging equity market investments, Emerging Markets Quarterly 1 (1): 17-46.

Cai, J. 1994. A markov model of switching-regime ARCH. Journal of Business and Economic Statistics 12 (3): 309-316.

De Frontenouvelle, P. 1999. Searching for the sources of ARCH behavior: Testing the mixture of distributions model. Chapter 13. In P. Rothman (ed). Nonlinear time series analysis of economic and financial data. Norwell, Mass.: Kluwer Academic Publishers.

De Santis, G., and Imrohoroglu S. 1997. Stock returns and volatility in emerging financial markets. Journal of International Money and Finance 16 (4): 561-579.

Diebold, F. X.; Lee, J. H.; and Weinbach, G. C. 1995. Regime switching with time-varying transition probabilities. In C. Hargreaves (ed). Nonstationary time series analysis and cointegration London, England: Oxford University Press.

Domowitz, I; Glen, J.; and Madhavan, A. 1997. Market segmentation and stock prices: Evidence from an emerging market. Journal of Finance 52 (3): 1059-1085.

Erb, C. B.; Harvey, C. R.; Viskanta, T. E. 1997. The making of an emerging market. Emerging Markets Quarterly 1 (1): 14-19.

Garcia, R. 1998. Asymptotic null distribution of the likelihood ratio test in Markov switching models. International Economic Review 39 (3): 763-788.

Garcia, R., and Perron, P. 1996. An analysis of the real interest rate under regime shifts. Review of Economics and Statistics 78 (1): 111-125.

Ghysels, E., and Garcia, R. 1996. Structural change and asset pricing in emerging markets. Working Paper. no. 34. Montreal: University of Montreal.

Goetzmann, W., and Jorion, P. 1999. Re-emerging markets. Journal of Financial and Quantitative analysis 34 (1): 1-32.

Gray, S. F. 1996. Modeling the conditional distribution of interest rates as a regime-switching process. Journal of Financial Economics 42 (1): 27-62.

Gray, S. F. 1997. An Analysis of Conditional Regime-switching Models. Working Paper. Duke University: 42 pages.

Hamilton, J. D. 1989. A new approach to the economic analysis of nonstationary time series and the business cycle. Econometrica 57 (2): 357384.

Hamilton, J. D. 1994. Time Series Analysis. Princeton, N.J.: Princeton University Press.

Hamilton, J. D., and Susmel, R. 1994. Autoregressive conditional heteroskedasticity and changes in regime. Journal of Econometrics 64 (1- 
2): 307-333.

Hansen, Bruce E., 1992. The likelihood ratio test under nonstandard conditions: Testing the Markov switching model of GNP. Journal of Applied Econometrics 7: S61-S82.

Harvey, C. R. 1995. Predictable risk and returns in emerging markets. Review of Financial Studies 8: 773-816.

Howell, M.J. 1993. Institutional investors and emerging stock markets. In S. Claessens and S. Gooptu (eds.). Portfolio investment in developing countries Washington, D.C.: World Bank: 78-87.

Kawakatsu H., and Morey, M. R. 1998. An empirical examination of financial liberalization and the efficiency of emerging market stock prices. Journal of Financial Research (Forthcoming).

Perron, P. 1989. The great crash, the oil price shock, and the unit root hypothesis. Econometrica 57 (6): 1361-1401.

Richards, A. J., 1996. Volatility and predictability in national stock markets: How do emerging and mature markets differ? International Monetary Fund, Staff Papers 43 (3): 461-501.

Richardson, M., and Smith,T. 1993. A test for multivariate normality in stock returns. Journal of Business 66 (2): 295-321.

Schaller, H., Van Norden, S. 1997. Regime-switching in stock market returns. Applied Financial Economics 7 (2): 177-191.

To, Minh C., and Assoe, K. G. 1996. Dynamique des relations entre les marchés boursiers nord-américains et les marchés en émergence. Canadian Journal of Administrative Sciences 13 (2): 132-145.

Turner, C. M.; Startz, R.; and Nelson, C.R. 1989. A Markov model of heteroskedasticity, risk, and learning in the stock market. Journal of Financial Economics. 25 (1): 3-22.

Van Norden, S., and Schaller, H. 1993. The predictability of stock market regime: Evidence from the Toronto stock exchange. Review of Economics and Statistics 75 (3): 505-510.

Van Norden, S., and Vigfusson, R. 1998. Avoiding the pitfalls: Can regimeswitching tests reliably detect bubbles? Forthcoming in P. Rothman (ed). Studies in Nonlinear Dynamics and Econometrics. Norwell, Mass.: Kluwer Academic Publishers.

Williamson, J. 1993. Issues posed by portfolio investment in emerging markets. In S. Claessens and S. Gooptu (eds). Portfolio investment in developing countries. Washington, D.C.: World Bank: 11-17. 